\title{
Improving Senior Knowledge Management in Ageing Societies: The Bakuntza Project
}

\author{
Urbano Isabel $^{1}$, Barandiarán Xabier $^{2}$, Guerra Igone $^{3}$ \\ ${ }^{1}$ Sinnergiak, social innovation, San Sebastian, Basque Country, Spain. \\ ${ }^{2}$ University of Deusto, Bilbao, Basque Country, Spain. \\ ${ }^{3}$ Sinnergiak, social innovation, San Sebastian, Basque Country, Spain.
}

\begin{tabular}{l} 
ARTICLE INFO \\
\hline Keywords: \\
Ageing workforce \\
knowledge transfer, \\
creating social value, \\
collaborative \\
environment, \\
intrapreneurship, youth \\
unemployment.
\end{tabular}

\section{Introduction}

The Bakuntza Project is a social innovation project focused on the design of an intergenerational model of senior knowledge transfer management to help companies face one of the major demographic challenges of the province of Gipuzkoa and its consequences for the competitiveness of the territory. It is a project that has been recently promoted within the framework of The Etorkizuna Eraikiz (Building the Future), a program run by the 
Provincial Council of Gipuzkoa. This program is an action-research process that is meeting the challenge of moving towards more collaborative forms of policymaking in the provincial Council of Gipuzkoa. The Bakuntza Project is the citizen's response to the call that The Provincial Council of Gipuzkoa made in 2016, in order to face the territory's strategic challenges identified within the framework of Etorkizuna Eraikiz program. The Bakuntza Project aims to provide a structured and integrated response to a series of challenges that affect Gipuzkoan society. The purpose of this case study was to examine the transfer back of knowledge through the design and promotion of a structured process of training-learning led by senior workers. This process is applied within a context of the promotion of entrepreneurship as a tool to achieve the improvement of young people's employability. The main contribution of this paper is the presentation of a synergic and structured process, which by stimulating the entrepreneurial activity of unemployed young people, promotes intrapreneurship projects based on the identification, evaluation and transfer of knowledge of senior employees. This document is divided into four sections. Firstly, the document presents the context in which the project is rolled out. The methodological framework of the senior knowledge management models is presented below, followed by the methodology applied in The Bakuntza project. Subsequently the results obtained are presented. Finally, the conclusions and some elements that invite debate are presented.

\section{Three Challenge in the Framework of Etorkizuna Eraikiz}

All of the challenge illustrated in this paper, will generate a series of macroeconomic impacts that will affect the economic competitiveness and welfare of the population of the Territory of Gipuzkoa. As such as, a reflection on age management and generational change is being promoted, because it is one of the priorities established in the Management Strategy of the Gipuzkoa Provincial Government for 2017 within the framework of the Etorkizuna Eraikiz Program. Etorkizuna Eraikiz is a long-term action-research process that, is meeting the challenge of moving towards more collaborative forms of governance in Gipuzkoa. In this context, the challenges of the territory are common with the rest of the other territorial agents. This article focuses on three shared challenges; the contribution of the elderly within the companies; the fall of entrepreneurial and intrapreneurial activity caused by the economic crisis and the great imbalance between supply and demand in the field of employment of young people.

\section{Senior Knowledge Management}

In recent years, numerous initiatives related to age and employment have been developed in Europe, approached from different perspectives and with different objectives. The demographic evolution and its effects have been the basis of many of these initiatives, driven largely by the European Union and also faced by a small territory called Gipuzkoa, in the Basque Country. The situation of Gipuzkoa is not very different from the rest of Europe . The projections for the year 2029 expect a fall in the population of more than 5\%. This means that in the next 15 years 36,000 inhabitants will be lost in the Basque Country, the most marked decrease in the working population as a whole, with a fall of more than $11 \%$, with some 52,000 people less in the working-age population. The result of the contrast between the expected data for the demand for employment and the potential supply of the active population, considering these circumstances, shows unmet needs of 9,000 people in 20292. In effect, these phenomena will have on one hand, a direct impact on the reduction of the rate of the working- 
age population and on the other hand, a displacement of the employed population towards older intervals, with the consequent increase in the percentage of senior workers.

In addition, we are faced with the increasing complexity of the knowledge needed in organizations due to the intensive use of technology and the dynamism of the markets. In many publications consulted it is argued that we are living in a knowledge economy in which intellectual capital is the main resource, and more important than labour, capital or other resources (Bou-Llusar C., J., \& Segarra-Ciprés, M. (2006)). In this context, it is important to bear in mind that work and life experience in general increases the social capital of older workers and whose knowledge is a key dimension of age management in organizations, due to their contribution to innovation and competitiveness. In fact, when employees retire they take their knowledge with them and consequently, the organization loses assets.

\section{Youth Unemployment}

Another common priority for Gipuzkoa is the increase in youth unemployment. The decline in economic activity caused by the economic crisis has triggered youth unemployment to reach historic levels. According to the analysis of youth employment carried out by the Basque Youth Observatory in October 2013, the youth unemployment rate in the Basque Country stood at $41.2 \%$, that means the unemployment rate of young people is almost double the rate in the general population.

\section{The Decrease in Intrapreneurship Rates}

Another priority of the territory is the decrease in entrepreneurship rates due to the recent economic crisis. According to the Global Entrepreneurship Monitor Report of the Basque Country Administration in 2015, the economic crisis has caused a deep regression in the entrepreneurial orientation of the Basque economy. In addition, the Global Entrepreneurship Monitor of the Basque Country in 2015, report states that the intrapreneurship rate in companies was $1.4 \%, 0.9 \%$ lower than in 2014, which shows us a greater fall in entrepreneurship in the case of companies than in the case of the general entrepreneurship of the population. Additionally, it should be noted that numerous reports show that, on average, the age of the entrepreneur is between 35 and 37 years in the Basque Country.

\section{The Barriers}

It seems evident that the growth of Gipuzkoa's economy will require the growing participation of older workers. However, according to the conclusions of the report "Youth versus seniority, the current situation of companies" made in 2013 by AEDIPE Catalonia among a sample of 2,000 Spanish companies, $75 \%$ of companies do not appreciate sufficiently the value of human capital when it exceeds 45 years. But in fact, Knowledge exists within people (Davenport, T.H.; Prusak, L., 1985), so it is needed to investigate the mix of framed experience, values, contextual information, and expert insight that has become the Knowledge of companies.

Otherwise, reviewing academic literature, we find that currently good management of knowledge is one of the greatest competitive advantages for companies (Ichijo, K., \& Nonaka, I. (2006)). It is widely accepted that knowledge has emerged as the most strategic resource of organizations, caused by the growing intensity and dynamism of competition across markets (Grant, Robert M. (1996)). Due to knowledge and intellectual capital having become both the primary bases of core competencies and the key to being competitive in the market (Lubit, R. 
(2001)). We can find numerous research projects about the benefits of sharing and integrating the knowledge held within companies. (Bou-Llusar C., \& Segarra-Ciprés, M. (2006)). There is no doubt that the process of knowledge transfer is a complex process. The studies confirm the existence of a series of barriers and obstacles, many of them based on stereotypes and topics without rigor, that condition the management of aging within the organizations as opposed to productivity and performance. One of the main barriers is the syndrome "not invented here" (Bou-Llusar C., \& Segarra-Ciprés, M. (2006)), due to the fact that people not only hesitate to share what they have, but they also hesitate to use knowledge of others. Another important barrier is the need to implement a knowledge-sharing culture in the companies, in order to facilitate the transfer of knowledge.

In addition, surprisingly, while Gipuzkoa maintains a high unemployment rate, problems begin to arise in some companies related to the lack of adequate profiles to cover certain jobs, showing a lack of profile alignment between supply and demand. It seems that, there is a great need on the one hand, to bring training programs closer to the needs of companies and on the other hand, to reduce the current imbalances in the professional orientation of young people towards their labor insertion.

\section{One Response to Three Challenges: Creating Social Value}

The Bakuntza project aims to provide a joint response to the three challenges described. Firstly, the mis-management of age and aging within companies, secondly, the decline in intrapreneurial activity caused by the economic crisis and thirdly the imbalance between training programs and needs of employers regarding labor insertion. These factors have led to the design and promotion of a structured process of training and learning, as well as to the intergenerational transfer of knowledge from the ageing workforce, carried out in a context of promoting entrepreneurship as an effective tool for the employment and professional development of unemployed young people. Considering the practical relevance of this research area, this study try to reduce the lack of management models of senior knowledge in societies in which the elderly are increasing and where knowledge is one of the main resources of competitiveness, analysing with special relevance, how to design a knowledge transfer process while creating social value. This vision of value creation specially emphasizes finding solutions aligned with the definition of social value of James A. P. Jr., Deiglmeier K. and Miller D., "a novel solution to a social problem or simply a solution more effective, efficient or sustainable than the existing solutions and whose created value corresponds mainly to society as a whole and not to private individuals." The creation of social value in the Bakuntza project is aimed at achieving an impact, not only solving each of the challenges, but also achieving the greatest degree of social value, by connecting the challenges, the stakeholders, the needs and the capacities of all the territory. Therefore, the Bakuntza project is presented as a creative instrument of social value whose result is not only creating a market value but the value generated according to improvement in the quality of life of people who live in Gipuzkoa.

\section{Methodology}

The Bakuntza Project was presented as a responsed to the 2017 call of the Etorkizuna Eraikiz Gipuzkoa Lab Program by a consortium of collaborative entities. The ISEA S.COOP., a nonprofit, innovation and entrepreneurship development center was a leader. The Upper 
Polytechnical School of University of Mondragon, a organitzation of teaching with public utility was a collaborating entity.

The broadest research question of the study was "Can an intergenerational model of knowledge transfer from senior employees towards young people be designed in order to create social value in entire territory?"

The purpose of this study is to design a mechanism to facilitate the capture of knowledge from the ageing workforce that exists in companies and how to transfer it to improve their competitiveness and to bring social value to the territory of Gipuzkoa.

In order to answer this research, question a comprehensive analysis of the literature and the research was conducted. First, the literature review provided a brief insight into the topics, highlighting the key elements respectively of age management and knowledge transfer, intrapreneurship and youth unemployment. Afterwards, the conclusions obtained from the first stage were shared with 25 companies in order to design a learning transfer process. Then the face of action began with four steps: step one, addressing the selection of age workforce teams and the recruitment of youth unemployment participants. Step two, the training step through active experimentation in entrepreneurship. The Bakuntza Project incorporates the training and active experimentation methodology because it constitutes an active learning experience integrated with a series of modules that allows the development of a business project in 6 months. This methodology allowed the participant to live a real entrepreneurial experience. Third step, the promotion period of the development plans of new business projects. The purpose of this step was to stimulate a total of 14 plans for the development of new business projects within the framework of an intergenerational transfer process involving senior staff who will act as a couch for one or more promoters. The fourth step was the time of socialization of the project. In this step the new projects were disseminated in the media as a whole (written press, radio and TV), as well as in social networks. The final face of this research-action project was the evaluation of the results. The results were analysed and discussed in order to answer the research question and to clarify how an effective process of transfer of senior knowledge could increase the rates of intrapreneurship, reducing the loss of knowledge through the transfer of intergenerational knowledge towards the unemployed thus generating social value.

\section{Results}

The review of the literature provided a brief perspective of the issues, highlighting that the management of knowledge transfer presents a great complexity and that the aging of the labor force will produce an unprecedented lack of competitiveness. Particularly important are the working age population who have the social capital of tacit or experiential knowledge necessary to maintain high levels of performance in complex technological, scientific fields. We also see a lack of attention on the part of companies that allow themselves to be led by unfounded stereotypes that contrast the age of workers with productivity levels and are not implementing age management models.

Regarding entrepreneurship, the sources consulted show that a person in the Basque Country, at the age of 39 years, starts entrepreneurial activity since many companies are created by people with considerable experience in the industry or sector in which they launch new companies. And this phenomenon has a universal character. Despite this, most of the basque public policies for the promotion of entrepreneurial activity have focused on training and 
supporting entrepreneurship projects, leaving the support for intra-entrepreneurs in the background.

The stage of action project presents the following results. 25 companies with 14 new projects promoting by 15 young unemployment have participate in the project. In qualitative terms, the Bakuntza project has allowed companies to put into practice active age management strategies that bring to light that the talent management of senior workers is likely to generate competitive advantages and social value.

It has allowed the aging workforce to show the importance of talent, work experience and vital senior workers in business competitiveness; to provide a motivating context for the last steps of their work activity within the framework of the launching of new business initiatives working with young people; helping the promotion of a new business culture related to older workers by creating a positive social opinion about the role of these people.

It has aligned unemployed youth, to improve their skills and competences until it is closer to the needs of companies; The promotion of entrepreneurial culture; Help them in their labor insertion by facilitating access to dynamic companies and, eventually, the possibility of redirecting their professional career by collaborating in business initiatives with potential for the future.

In relation to the model of transfer, trust is considered by many autors as an important key element for effective knowledge transfer. According to the results, an environment of intergenerational learning facilitates the appearance of trust between the participants.The training and methodology of active experimentation through teamwork, meetings and workshops with a systematic support process offered by senior staff of companies are shown as key elements that allow the effective transfer of knowledge; The improvement of skills and competences until they are closer to the needs of companies; The promotion of entrepreneurial culture helps them in their labor insertion by facilitating access to dynamic companies and, eventually, the possibility of redirecting their professional career by collaborating in business initiatives with potential for the future.

\section{Conclusion}

Considering the practical relevance of this research area, this study represents an attempt to narrow the lack of management models of senior knowledge in societies with increasing elderly and where knowledge is a main resource of competitiveness. (Bellini, A., Aarseth, W., \& Hosseini, A. (2016)). The framework offered by the Etorkizuna Eraikiz program, as a collaborative government instrument, moves away from the individual focus, establishing spaces for participation, debate and listening that allow sharing the challenges of the territory and the ways in which they are addressed. A collaborative environment in which the main challenges are shared, and all the capabilities are known, facilitates the creation of creative solutions of social value. By increasing the focus on age management mechanisms with an adequate knowledge transfer strategy, it is possible to improve organizational performance in terms of reducing the loss of talent, improving the results of intrapreneurship and improving the labour training of young people while adjusting it to the needs of companies. Thus, among the actions to be considered in order to ensure effective management of age in companies, it is worth highlighting the formalization of a system for transferring knowledge among people who retire by creating mixed work groups for the transfer of experience. 
The Bakuntza Project presents a high rate of scalability for the possible transfer of experience and knowledge acquired to other geographical areas, given that the project aims to provide a structured response to a series of major challenges that affect society from Gipuzkoa.

In conclusion, it is highly recommended to understand and manage the senior knowledge transfer process in organizations as a share challenge because it has a great impact on the competitiveness of companies but also is an essential key to enhance the territory's competitiveness. Thus, is recommended taking a systemic approach when addressing knowledge retention problems and seeking integral solutions.

The main limitation of this work is that the research does not have ex-post evaluation instruments, so the medium-term impact of the project is unknown.

We also suggest ways for future research to explore new models for transferring the aging knowledge of the labor force in order to generate new frames of reflection and debate that give rise to efficient and easily generalizable systematized models.

A discussion is provided on the shift in focus from the loss of the aging workforce as a individual problem to the evolution towards a more global approach to the innovation initiative that will increase social value, with a conclusion in which the role of the environment of collaboration is essential in the stimulation of social innovation solutions.

\section{References}

[1] Auerswald, Philip Edgar, Creating Social Value (January 8, 2009). Stanford Social Innovation Review, Spring 2009. Available at SSRN: https://ssrn.com/abstract $=1376425$

[2] Bellini, A., Aarseth, W., \& Hosseini, A. (2016). Effective knowledge transfer in successful partnering projects. Energy Procedia, 96, 218-228.

[3] Carlos Bou-Llusar, J., \& Segarra-Ciprés, M. (2006). Strategic knowledge transfer and its implications for competitive advantage: an integrative conceptual framework. Journal of knowledge management, 10(4), 100-112.

[4] DeLong D.W. (2004). Lost Knowledge: Confronting the Threat of an Aging Workforce, New York: Oxford University Press

[5] Grant, Robert M. Prospering in dynamically-competitive environments: Organizational capability as knowledge integration. Organization science 7.4 (1996): 375-387.

[6] Ichijo, K., \& Nonaka, I. (2006). Knowledge creation and management: New challenges for managers. Oxford University Press

[7] Lubit, R. (2001). The keys to sustainable competitive advantage. Organizational dynamics, 29 (3), 164-178.

[8] Thomas H. D. and Prusak L., (1998). Working Knowledge: How Organizations Manage What They Know, Harvard Business School Press. 